\title{
Aggregative Behavior of Cohesive Magnesium Carbonate Powders during Fluidization and Aerated Discharge ${ }^{\dagger}$
}

\author{
G. Donsì, G. Ferrari, M. Poletto \\ and P. Russo \\ Dipartimento di Ingegneria Chimica e \\ Alimentare, Università degli Studi di Salerno*
}

\begin{abstract}
In this paper we studied the aerated discharge of two magnesium carbonate powders differing in their average diameter and particle size distribution. These samples were characterized by means of fluidization experiments and rheology shear tests carried out in a rotating shear cell. In the hopper discharge experiments, besides the discharge rates and the mass of residual solids as a function of the aeration rate, the aggregative behavior was observed by means of photographic techniques. Solids aggregates were actually visible within the aerated beds of solids during the fluidization experiments and in the streams of the discharging solids. Experimental data on the powder flow properties and on fluidization were analysed in order to permit evaluation of the aggregate diameters. These values compared fairly well with the aggregate diameters observed and made it possible to evaluate the voidage values outside the aggregates. These results were used in a modified form of the De Jong and Hoelen [9] equation to predict the solids discharge rate with a reasonable degree of accuracy.
\end{abstract}

\section{INTRODUCTION}

The discharge of fine powders from hoppers is hindered by either fluid dynamic interactions (for example, see [1]) or cohesive interparticle interactions. The discharge rate of these powders is actually overestimated by the Beverloo et al. [2] equation:

$$
W_{s}=0.58\left(1-\varepsilon_{b}\right) \rho_{p} g^{0.5}\left(d_{o}-1.5 d_{p}\right)^{2.5}
$$

where $W_{s}$ is the solids discharge rate, $\varepsilon_{b}$ is the voidage of the bulk solids, $\rho_{s}$ and $d_{p}$ are the density and the mean diameter of the solid particles, $d_{o}$ is the outlet diameter and $g$ the acceleration due to gravity. The significance of fluid dynamic and cohesive interactions depends mainly on the particle diameter. Fluid dynamic interactions appear to set in for particle diameters which are somewhat larger than those for which cohesive interparticle forces appear to be effective. Geldart and Williams [3] extended the Geldart [4] classification of powders valid for fluidization to

* Via Ponte Don Melillo, I-84084 Fisciano (SA), Italy

$\dagger$ Accepted: August 22, 2003 the discharge behavior. Accordingly, Group A powders can be referred to as those for which fluid dynamic interactions affect the discharge, and Group C powders as those for which cohesive forces can produce irregular flow. This paper, in particular, regards the discharge of cohesive powders.

The effect of cohesive forces on the discharge behavior also depends on powder consolidation phenomena which appear as a consequence of compression forces acting on static and flowing solids. Such disturbing effects consist primarily in arching and ratholing phenomena. An evaluation of the storage conditions that can produce such phenomena was first given by Jenike [5].

The injection of air can produce favorable effects in the flow of fine powders. Air can be injected in different ways such as near the outlet of conical hoppers [6] or through the flat bottom of bins [7]. For Group $\mathrm{C}$ powders, the effect of aeration, regardless of how the air is injected, is that of promoting the flow which does not occur at zero air flow rate. Various attempts have been made to obtain valid equations for the correlation of the discharge rates of free-flowing solids at the different operating conditions which can be obtained at low, [1], intermediate [8], [9] and elevated 
[30] raration rates. Some terms appearing in these equations such as the pressure gradient in the proxWimity of the hopper outlet or the air flux through the same orifice appear difficult to evaluate. Moreover, from experiments carried out in similar aerated discharging devices on freeflowing [11] and cohesive powders [12], it appears that a different discharge behavior is found in the two cases.

Experiments on a corn starch powder [13] demonstrated that the first effect of aeration is that of breaking up the arches at the outlet and preventing their subsequent formation. At low and increasing aeration levels, this powder shows rat-holing and core flow (funnel flow). The effect of solids flow promotion by increasing aeration is to mobilize the superficial layers of solids involved in the funnel flow mechanism. Only very high aeration rates are able to fluidize the solids and to produce flow fields similar to those found with aeratable powders at high aeration. In spite of such complex phenomenology, the corn starch discharge rate under aeration is roughly predicted by the above-mentioned equations. It is also possible to extend some simplifications to these solids that make the use of the De Jong and Hoelen [9] equation possible in a predictive way. Indeed, according to their equation, the discharge rate is expressed as the following:

$$
W_{s}=0.55 \rho_{p}\left(1-\varepsilon_{b}\right)\left[a\left(\frac{Q_{f 0}}{\varepsilon_{b}}-\frac{Q_{s o}}{1-\varepsilon_{b}}\right)^{2}+b\left(\frac{Q_{f 0}}{\varepsilon_{b}}-\frac{Q_{s 0}}{1-\varepsilon_{b}}\right)\right]^{0.5}
$$

where

$$
a=\frac{1.75}{12} \frac{\rho_{f} d_{o}}{\rho_{p} d_{p} \varepsilon_{b}}\left(1-1.5 \frac{d_{p}}{d_{o}}\right)^{4}, b=\frac{150}{8} \frac{\pi \mu_{f} d_{o}^{3}\left(1-\varepsilon_{b}\right)}{\rho_{p}\left(d_{p} \varepsilon_{b}\right)^{2}}\left(1-1.5 \frac{d_{p}}{d_{o}}\right)^{4},
$$

$Q_{f_{0}}$ and $Q_{s o}$ are the volumetric flow rates of the gas and of the solid through the outlet orifice, $\rho_{f}$ and $\mu_{f}$ are the gas density and viscosity. Some model evaluations based on gas pressure profiles allowed us to verify that, in the gas-mass balance during discharge, the amount of air percolating through the bed is negligible and, therefore, the gas rate through the orifice is equal to the sum of the aeration rate, $Q_{f}$, and of the interstitial air brought in by the solids, that is

$$
Q_{f o}=Q_{f}+Q_{s o} \varepsilon_{b} /\left(1-\varepsilon_{b}\right)
$$

Furthermore, no effect of gravity is included in equation (2) and, therefore, by comparison with equation (1) and use of equation (2), it can be modified into:

$$
W_{s}=0.55 \rho_{p}\left(1-\varepsilon_{b}\right)\left[a\left(Q_{f} / \varepsilon_{b}\right)^{2}+b Q_{f} / \varepsilon_{b}+g\left(d_{0}-1.5 d_{p}\right)^{5}\right]^{0.5}
$$

The comparison between equation (4) and the experi- mental results obtained with corn starch is satisfactory. According to the general classification of powders as given by Schulze [14], however, the corn starch powder tested belongs to the easy flowing region as indicated by the flow function in Figure 1. In this figure, it is compared among others with the flow function of a free-flowing FCC powder for which equation (4) also gave satisfactory results. The abovediscussed framework, therefore, might change if we use powders with poorer flow properties such as those found for the two magnesium carbonate powders reported in Figure 1.

From the standpoint of fluidization characteristics, according to Wang et al. [15], those of corn starch are among the most common for cohesive powders. This powder shows a velocity range of defluidized state at the lower aeration rates, above the minimum necessary to form a moving slug. Pacek and Nienow [16] associated this situation to the formation of aggregates whose fluidization starts at higher aeration rates. Pressure drops lower than the bed weight can also be found under agglomerate fluidization at decreasing aeration rates and were attributed to a partial adhesion of particle agglomerates to the column walls [17]. The hypothesis of agglomerate fluidization is frequent in the literature and has also been introduced to explain the effect of techniques inducing the homogeneous fluidization of cohesive powders (see, for example [18]).

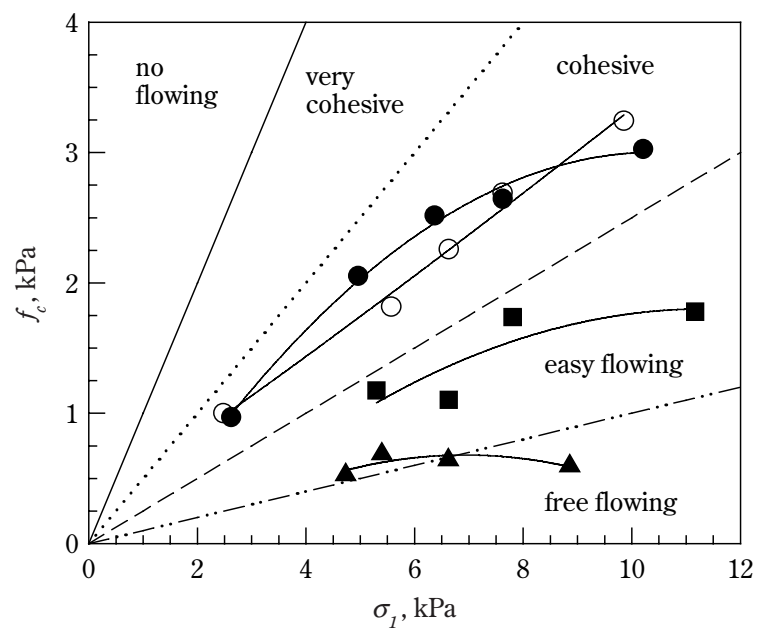

Fig. 1 Flow functions of the two magnesium carbonate powders used in this work compared with those of the powders used by Donsi et al. [13] and with the powder classification as given by Schulze [14]: $\mathbf{\Delta}$, FCC $45 \mu \mathrm{m}$; $\mathbf{\square}$, corn starch 19 $\mu \mathrm{m} ; \bullet, \mathrm{MgCO}_{3} 14 \mu \mathrm{m} ; \bigcirc, \mathrm{MgCO}_{3} 3 \mu \mathrm{m}$. 


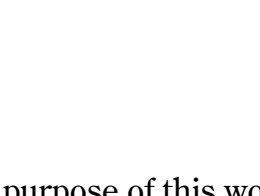

The purpese of this work is to extend the discharge axpriments to include two magnesium carbonate coflesive powders in order to verify whether the same mechanisms promoting the discharge of corn starch could apply or, instead, if some consideration should be given to the formation of powder agglomerates also in the description of solids discharge rates.

\section{EXPERIMENTAL}

\section{Apparatus}

A schematic of the aerated bin used is given in Figure 2. The bin had cylindrical walls of $3 \mathrm{~mm}$ in thickness made of transparent Perspex to allow a visual inspection of the interior. It was $520 \mathrm{~mm}$ high and $147 \mathrm{~mm}$ ID. At the bottom the bin was equipped with a gas distributor, $\mathrm{D}$, consisting of 10 -mm-thick sintered plate made of a $10-\mu \mathrm{m}$ brass powder. The wind-box, WB, below the distributor was made of stainless steel and was equipped in the middle with a vertical duct with increasing cross-section downwards to allow the solids to discharge. An interchangeable orifice, $\mathrm{O}$, was mounted at the top of this duct, at the distributor level. This device created some space

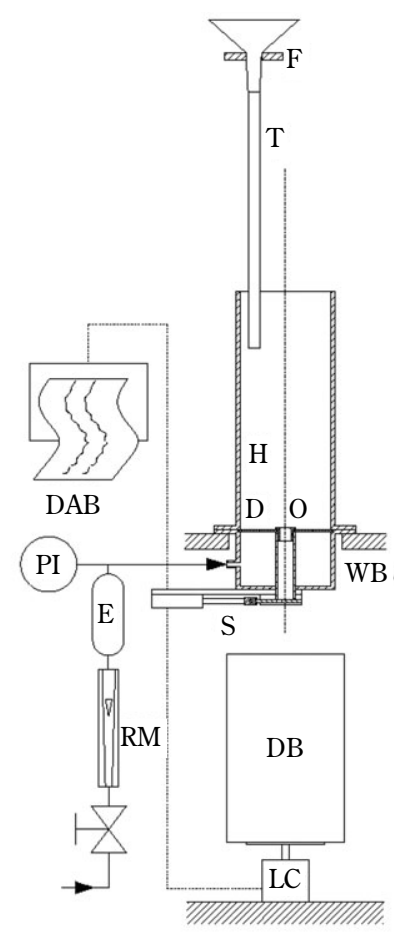

Fig. 2 Experimental apparatus: D, gas distributor; DAB, data acquisition board or chart recorder; DB, discharge bin; $\mathrm{E}$, desiccator; F, funnel; H, bin; LC, load cell; O, outlet orifice; $\mathrm{PI}$, pressure indicator; RM, rotameter; $\mathrm{S}$, slide lock; $\mathrm{T}$, tube; WB, wind-box. between the discharging solids and the duct wall, thus allowing atmospheric pressure to set around the falling solids. At the exit of the duct, a pneumatically operated sliding valve, S, was used to close the outlet while loading the solids into the bin. The discharged solids were collected in a bin, DB, placed on a load cell, LC, based on a strain-gage bridge, operating in the range $0-50 \mathrm{~N}$. The air flow rate through the distributor was regulated by a valve and measured with a rotameter, RM. Before entering the system, the air was dehumidified in a desiccator, $\mathrm{E}$.

The fluidization curve of the powder was studied in a 50-mm-ID glass column fitted with a pressure tap located on the wall just above the sintered glass distributor.

The solids flow functions were studied in a rotating Peschl shear tester that was modified to extend the shear stress measurement to consolidation levels low enough to be compared with what might be experienced by the powder during the aerated discharge. To this purpose, a cinematic chain was designed and built to partially sustain the weight of the cell lid that, otherwise, is the minimum applicable load to the powder sample.

\section{Materials}

In the experiments, two magnesium carbonate powders of 14 and $3 \mu \mathrm{m}$ average diameter were used. Scanning electron microscopy pictures of these powders at a magnification ratio of 1000 are given in Figure 3. For both powders, the particle density was $2600 \mathrm{~kg} \mathrm{~m}^{-3}$. In contrast, the size distributions of the two powders were quite different. The size distribution of the $14-\mu \mathrm{m}$ powder was in the range $2-40 \mu \mathrm{m}$ for the $80 \%$ of the mass and it was bimodal with two peaks at 3 and $20 \mu \mathrm{m}$. The size distribution of the 3$\mu \mathrm{m}$ powder was in the range 1 and $11 \mu \mathrm{m}$ for the $80 \%$ of the mass and it was unimodal. The powder bulk density seems to be strongly affected by the differences in particle size distributions, in fact, it was about $950 \mathrm{~kg} \mathrm{~m}^{-3}$ for the $14-\mu \mathrm{m}$ powder and about 650 $\mathrm{kg} \mathrm{m}^{-3}$ for the $3-\mu \mathrm{m}$ powder. A possible interpretation for this can be found in Figure 3a which shows that, in the $14-\mu \mathrm{m}$ powder, the finer particles tend to stick to the larger ones (see, for example [19]). This can give rise in this powder to both a less porous (larger bulk density) and a less homogeneous structure than in the unimodal $3-\mu \mathrm{m}$ powder. The size distribution and fluidization behavior assign these powders to group C of the Geldart [4] classification. In addition, the flow functions of the two powders reported in Figure 1 indicate that their flow behavior is in the 

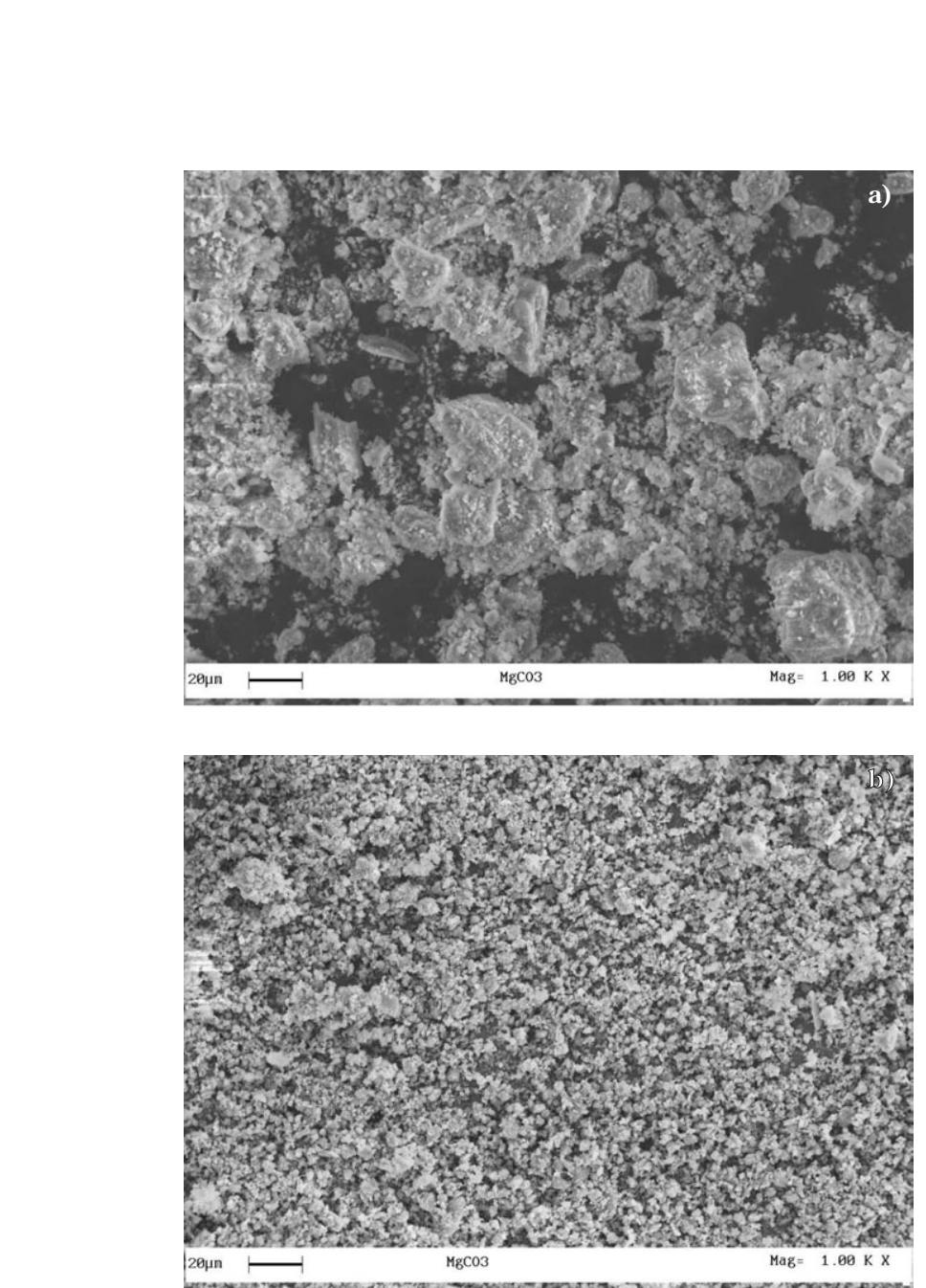

Fig. 3 SEM images of the magnesium carbonate powders tested at 1000 magnifications: a), $14-\mu \mathrm{m}$ powder; b), $3-\mu \mathrm{m}$ powder.

range of significantly cohesive powders. In spite of the differences in particle size distributions and bulk density, it is possible to observe that the flow functions are very similar to each other. Figure 4 shows the cohesion values and the internal friction angles found from the yield loci at increasing consolidation. The former of these two parameters increases with consolidation, while the latter seems almost unaffected by it.

\section{Procedures}

The bin was loaded from the top through a funnel, F, in Figure 2, connected to a large Perspex tube, T, which plunged into the bin. The measurements were made by loading a fixed amount of solids of about 5.0 $\mathrm{kg}$ for the $14-\mu \mathrm{m}$ powder and of about $3.9 \mathrm{~kg}$ for the $3-\mu \mathrm{m}$ powder. The time series of the mass of solids discharged were acquired by a PC with a data acquisition board, DAB.
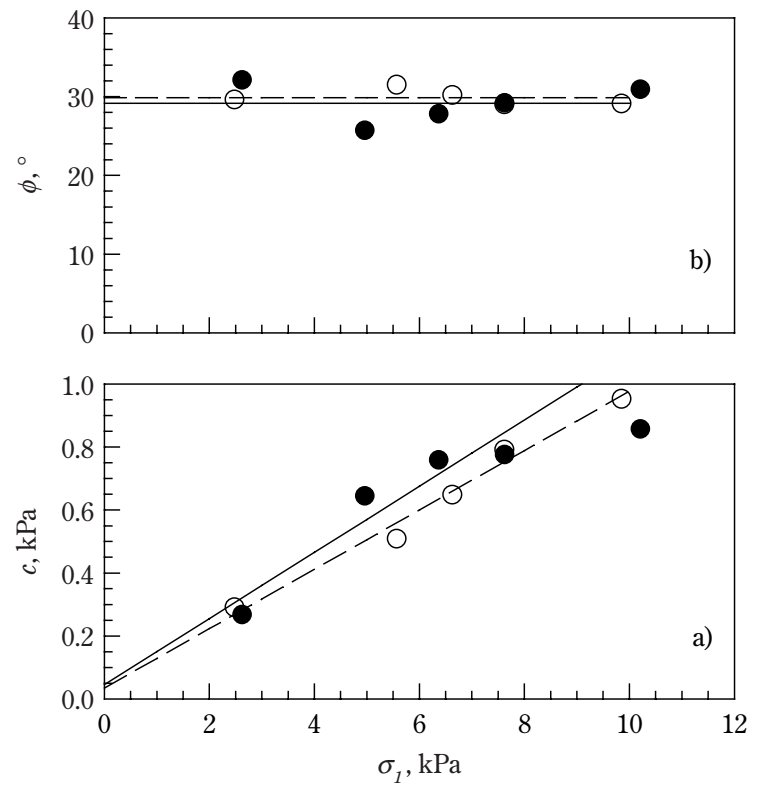

Fig. 4 The cohesion, a), and the angle of internal friction, b), evaluated for the two magnesium carbonate powders at increasing consolidation: $\bullet$, experimental data $14-\mu \mathrm{m}$ powder; $\bigcirc$, experimental data $3-\mu \mathrm{m}$ powder; - , regression line $14-\mu \mathrm{m}$ powder; - - -, regression line $3-\mu \mathrm{m}$ powder.

Images of the discharging streams of solids were obtained by means of a high-resolution Nikon Coolpix 990 digital camera and a stroboscopic light that, with its very short light pulses, can "freeze" the solids motion. To obtain a single light pulse during the exposure, the period between subsequent flashes of the stroboscopic light was set equal to the exposure time.

\section{RESULTS}

\section{Fluidization curves}

Figure 5 shows the fluidization curves (Figure 5a) and the corresponding expansion curves (Figure 5b) of the two magnesium carbonate powders obtained in the $50-\mathrm{mm}$ glass fluidization column with an initial bed height of about $140 \mathrm{~mm}$. This height corresponds to a mass of $0.30 \mathrm{~kg}$ of the $14-\mu \mathrm{m}$ powder and to a mass of $0.21 \mathrm{~kg}$ of the $3-\mu \mathrm{m}$ powder and was coherent with the marked bulk density differences noted above in the shear test experiments. A double scale has been used to represent data at low and high aeration to improve visualization of the phenomena observed. The fluidization curves for the two powders tested show several similarities. At low aeration rates, pressure drops increase up to gas superficial velocities of about $7 \mathrm{~mm} \mathrm{~s}^{-1}$ for the $14-\mu \mathrm{m}$ powder and of about 13 


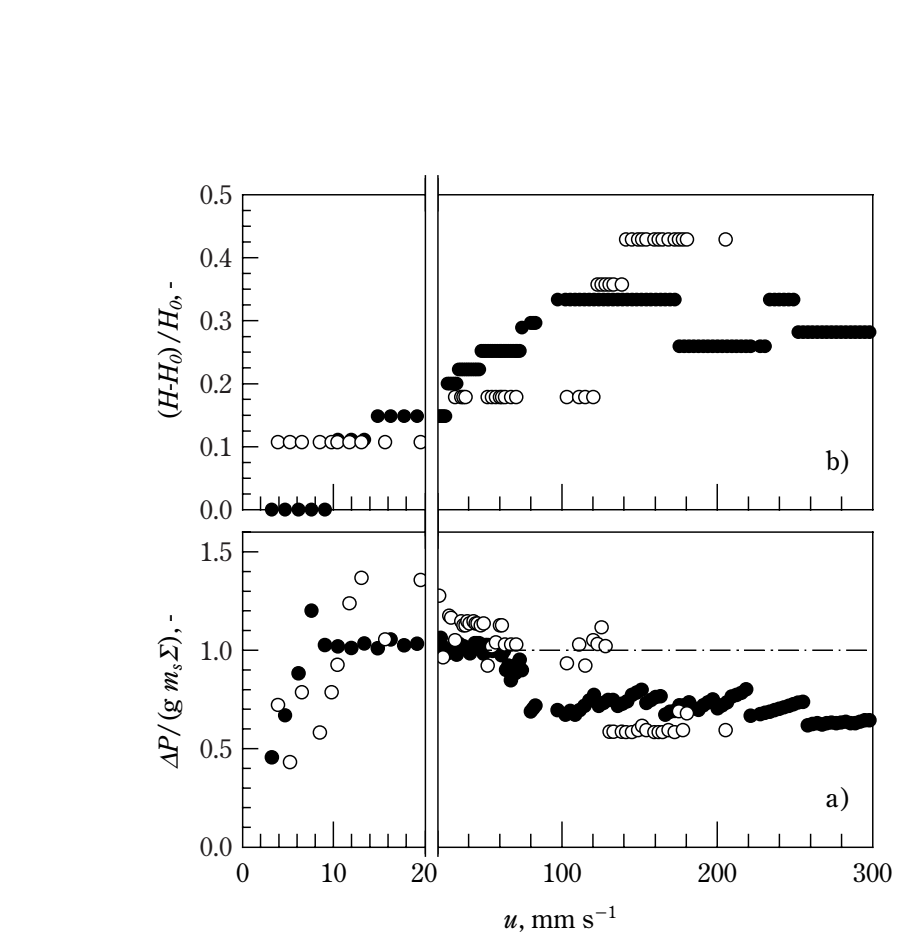

Fig. 5 Fluidization and expansion curve for carbonate powders in 50-mm-ID fluidization column: $\bullet, 14-\mu \mathrm{m}$ powder; $\bigcirc, 3-\mu \mathrm{m}$ powder.

$\mathrm{mm} \mathrm{s}^{-1}$ for the $3-\mu \mathrm{m}$ powder. At these aeration velocities, a maximum of pressure is observed of about 1.2 and 1.4 times the bed weight value for the two powders, respectively. In the experiment, the pressure drops in excess of the bed weight corresponded to the formation of a rising slug that could only be kept within the column by breaking it. The slug was not a single piece but rather several horizontal cracks crossed its body at intervals of few centimeters. After the slug formation and breakage, the behavior of the two powders differed slightly. The $14-\mu \mathrm{m}$ powder bed immediately expanded to about $30 \%$ value in a fairly large velocity range up to $60 \mathrm{~mm} \mathrm{~s}^{-1}$ and, correspondingly, the pressure drops kept constant at the bed weight value. In this velocity range, therefore, the powder could be considered fluidized in spite of the absence of evident powder motion. Closer inspection of the bed revealed an evident network of cracks defining aggregates of a few millimeters in diameter as shown in Figure 6a. In contrast, the $3 \mu \mathrm{m}$-powder, before expanding and being considered fluidized, showed a fairly wide range between 8 and $65 \mathrm{~mm} \mathrm{~s}^{-1}$ in which unstable slugs formed and pressure drops fluctuated between values equal to the bed weight and $10 \%$ higher. Large horizontal cracks were still present as shown in Figure 6c. This powder expanded and could be considered fluidized in the gas superficial velocity range between 65 and $130 \mathrm{~mm} \mathrm{~s}^{-1}$. In
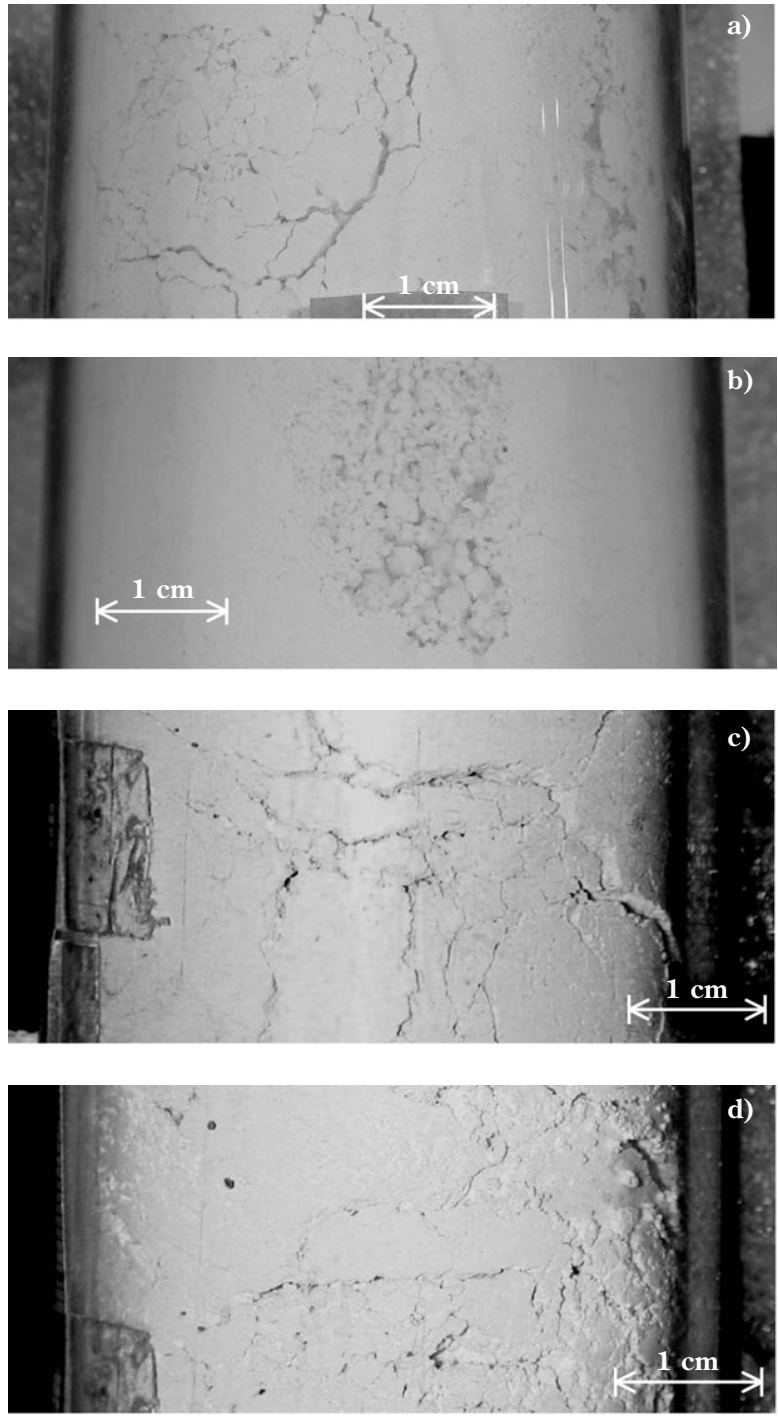

Fig. 6 Aggregation during aeration for magnesium carbonate powder: a) $14-\mu \mathrm{m}$ powder, $u=27.9 \mathrm{~mm} \mathrm{~s}^{-1}$; b) $14-\mu \mathrm{m}$ powder, $u=120 \mathrm{~mm} \mathrm{~s}^{-1}$; c) $3-\mu \mathrm{m}$ powder, $u=35 \mathrm{~mm} \mathrm{~s}^{-1}$; d) 3 $\mu \mathrm{m}$ powder, $u=114 \mathrm{~mm} \mathrm{~s}^{-1}$.

these conditions the cracks appeared more uniform, as shown in Figure 6d. For both powders, the pressure drops decreased at values of about $30-40 \%$ lower than the bed weight at the highest gas velocities, suggesting the onset of channeling phenomena. The bed also continued to expand in this aeration range. A typical channeling region at high aeration is shown in Figure $\mathbf{6 b}$, where the high gas shear action smoothes the aggregates shapes.

\section{Discharge experiments}

Several time series of the discharged mass of solids were obtained at different aeration rates for both magnesium carbonate powders. An example of these is 
roportad in Figure 7, which was obtained for the 14$\mu$ mowder at a nominal aeration velocity of $u=21$ $\mathrm{wm} \mathrm{s}^{-1}$. Some common features of mass time series can be summarized. At the very beginning, it was possible to identify a peak in the load trace due to the impact in the collection bin of the solids contained in the diverging channel for the solids discharge before the slide lock opened. Following this, an almost stationary discharge rate, appearing as a linear section of the curve in Figure 7, was observed in the first part of the discharge experiment. Only in the latest part of the experiment was it possible to observe time variations of the solids discharge rate, appearing as a convex portion of the discharge curve in Figure 7. These variations can be attributed to the onset of a system sensitivity to the changing bed height. The width of the mass range for which stationary discharge rates were observed tends to increase with the aeration rate, and this range of data was used to evaluate solids discharge rates. As an example in Figure 7, the range adopted is that contained in the hatched area, and the dashed line derives from the linear interpolation of these data. At all aeration conditions, solids discharge rates were assumed to be the slopes of the interpolating lines in the constant discharge rate region. Solids discharge rates evaluated in this way are reported in Figure 8a as a function of aeration. The final values of the discharged mass in

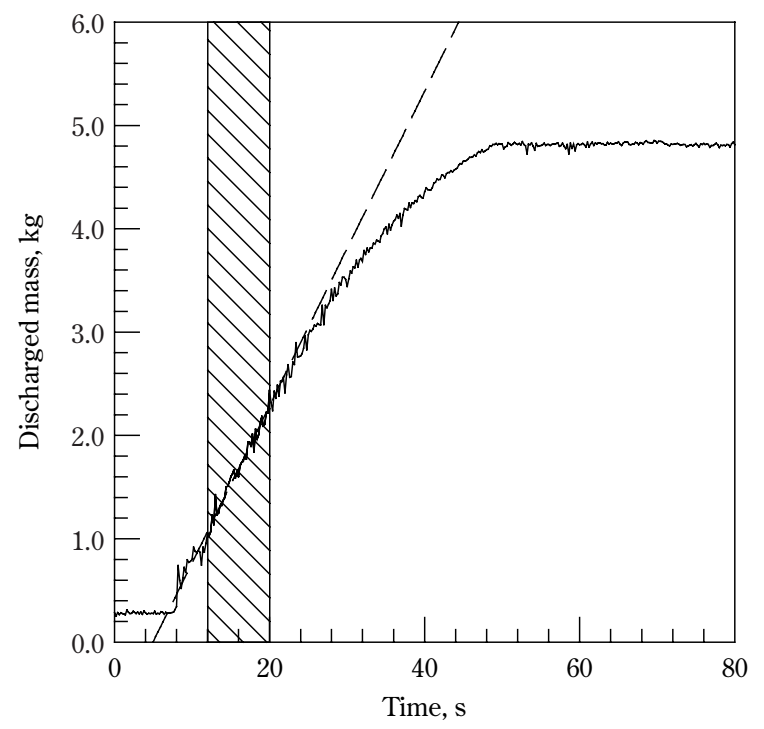

Fig. 7 Mass of discharged solids as a function of time for $14-\mu \mathrm{m}$ powder at $u=21 \mathrm{~mm} \mathrm{~s}^{-1}$ : — , experimental data; - - -, linear interpolation of data in the constant discharge rate range within the dashed area.
Figure 7 and in the other mass time series did not generally correspond to the loaded mass of solids due to a residual load within the bin. The values of these residual masses relative to the loaded mass are given in Figure $\mathbf{8 b}$ as a function of the aeration rate.

From Figure 8, it is possible to observe that aeration affected both the average solids discharge rate (Figure 8a), by increasing it, as well as the amount of the residual mass in the bin at the end of the discharge (Figure 8b), by decreasing it. At low rates, aeration was more effective on the $3-\mu \mathrm{m}$ powder, while at high rates, aeration was more effective on the 14- $\mu \mathrm{m}$ powder both in terms of higher solids discharge rates and a smaller fraction of residual solids at the end of the discharge experiment. If compared with solids fluidization curves, it appears that the attainment of the maximum value of the solids discharge rate seems to be related to the effective solids fluidization rather than to the establishment of larger pressure drops through the aerated bed. This is in agreement with what has been found to date on the effects of aeration. In spite of the generally similar trends of these variables with those found previously with corn starch, it must be noted that magnesium carbonate never showed the formation of rat-holes. On the contrary, the solids surface during the discharge was always flat and never showed the formation of a central depression with the onset of the

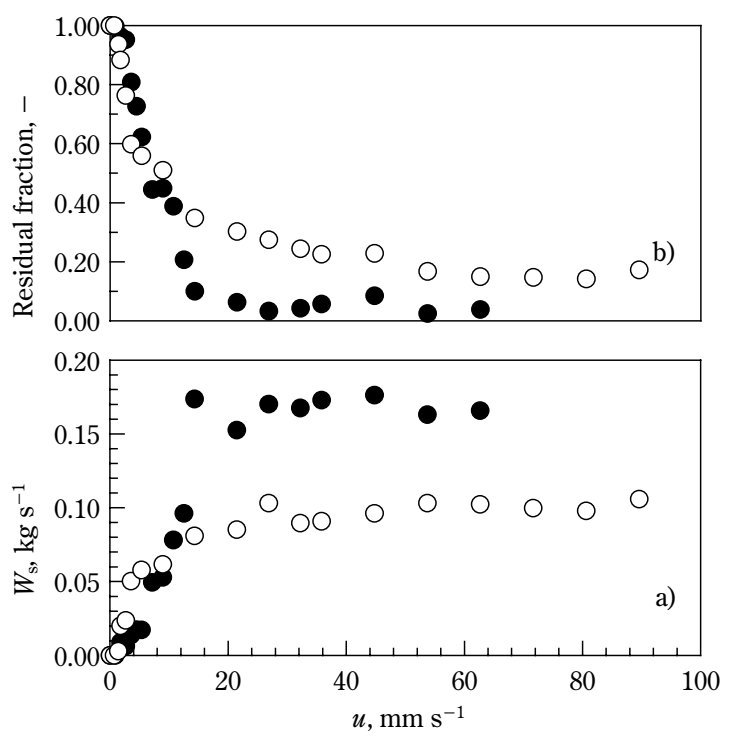

Fig. 8 The solids discharge rate and the residual mass as a function of aeration: $\bullet, 14-\mu \mathrm{m}$ powder; $\bigcirc, 3-\mu \mathrm{m}$ powder. 
paric

centripetad motion which characterizes the funnel flob negime.

\section{Visualization of the discharging stream}

Single high-resolution shots of the discharging solids were taken and are shown in Figure 9 at different aeration velocities that span the entire aeration range tested for the discharge experiments. The analysis of Figure 9 indicates that aeration does not significantly affect the size of the discharging aggregates. Aggregates are very fragile and most of them break in the discharge process. However, the largest aggregates which are found in the discharging stream should be representative of the aggregates present in the bed of solids prior to discharge. All these aggregates showed sizes between 1 and $6 \mathrm{~mm}$ and accorded
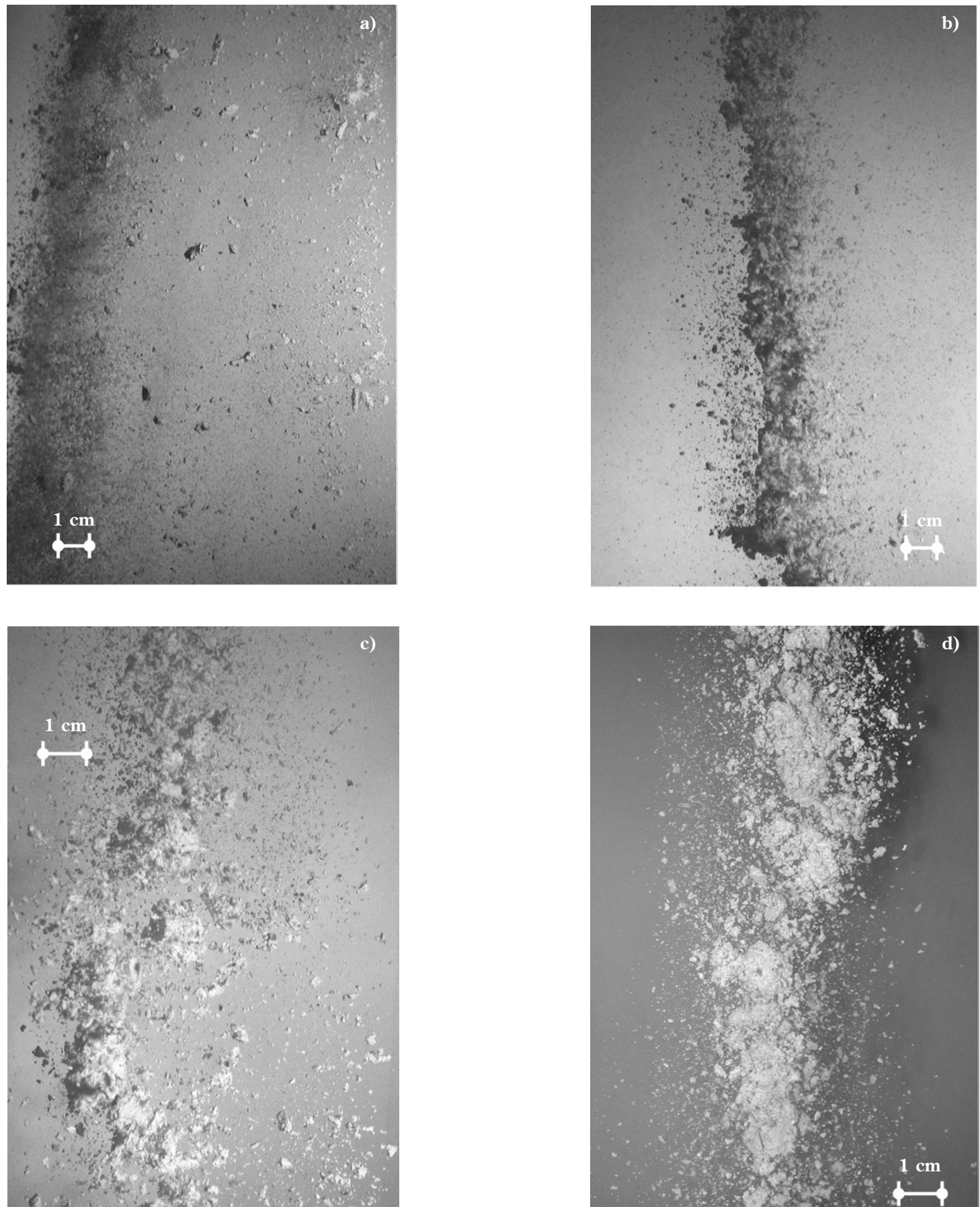

Fig. 9 Aggregation during discharge of magnesium carbonate powder: a) $14-\mu \mathrm{m}$ powder, $u=9.0 \mathrm{~mm} \mathrm{~s}^{-1}$; b) $14-\mu \mathrm{m}$ powder, $u=30 \mathrm{~mm} \mathrm{~s}{ }^{-1}$; c) $3-$ $\mu \mathrm{m}$ powder, $u=72 \mathrm{~mm} \mathrm{~s}^{-1}$; d) $3-\mu \mathrm{m}$ powder, $u=300 \mathrm{~mm} \mathrm{~s}^{-1}$. 
wath that which had been observed in Figure 6. It is worth noting that the discharge of aggregates also Wappeared at aeration rates at which their presence was not detected by direct observation of the fluidization column.

\section{DISCUSSION}

All the fluidization and discharge features described above regarding the discharge of magnesium carbonate differ considerably from what had been previously observed by Donsì et al. [13] on corn starch and reported in the introduction. In particular, the fluidization behavior of magnesium carbonate shows an inversion in the sequence of fluidization and channeling. In this respect, the fluidization scheme is very similar to that found by Wang et al. [15] with limestone. In this case also, the size of aggregates was larger than $1 \mathrm{~mm}$. In the solids discharge with the magnesium carbonate, we did not observe the changing behaviors found with corn starch. In particular with the $14-\mu \mathrm{m}$ powder, we observed an almost complete discharge of the loaded powders at all useful aeration rates. With the $3-\mu \mathrm{m}$ powder, in contrast, some solids residues tended to remain at all the aeration rates tested.

A possible interpretation of the aggregate formation could follow the hypothesis that the aggregates detach along surfaces of average weaker interactions when the beds starts to expand and, more precisely, when the first slug forms and horizontal cracks are visible in the bed. In these conditions, aggregates can form by detaching from the bulk in the lower portion of the slugs wherever the aggregate weight is greater than the attraction force, $F_{c}$, of the contact between the aggregate and upper lumps of the solids. The aggregate formation, therefore, should proceed by separating one by one towards the top of the bed. Assuming spherical aggregates, the force balance on the detaching aggregate is:

$$
\frac{p d_{a}^{3}}{6} \rho_{p}\left(1-\varepsilon_{i}\right) g=F_{c}
$$

where $d_{a}$ and $\varepsilon_{i}$ are the aggregate diameter and its internal voidage. In principle, equation (5) should also include some other force contributions to account for the fluid dynamic forces. It is possible, however, that due to local voidage non homogeneities, this force might be lower or even higher than the particle weight according to the local gas velocity. In any case, being close to the fluidization condition, these forces are of the order of magnitude of the gravity force and, therefore, equation (5) accounts correctly for the range of the forces involved in the aggregate formation. The value of $F_{c}$ might be related to the bulk properties of the powder and, in particular, to the tensile strength of the powder. In fact, when the aggregates are compacted, the relationship between the tensile stress, $\sigma_{t}$, and $F_{c}$ might be described by the force balance across a plane separating two aggregate layers:

$$
\sigma_{t}=F_{c} n_{c}
$$

where $n_{c}$ is the contact density that, in turn, can be expressed as:

$$
n_{c}=k d_{a}^{-2}
$$

where $k$ is the number of the effective contacts between an aggregate and its neighbors on another layer. Empirical functions $k(\varepsilon)$ were developed by authors such as Rumpf [20] and Kendall et al. [21] in the case of packing of rigid spherical particles. In that case, the maximum value for $k$ at the minimum allowed voidage was about 3 . As this value is close to the maximum reasonable value, it was assumed also in the case of the aggregates. Combining equations (5) to (7), it is possible to correlate the aggregate size starting from the bulk tensile strength of the powder:

$$
\frac{p d_{a}^{3}}{6} \rho_{p}\left(1-\varepsilon_{i}\right) g=\frac{s_{t} d_{a}^{2}}{k}
$$

Given an ideal Coulomb elastic-plastic solid, its yield will follow the equation:

$$
t=s \tan f+c
$$

where $f$ is the angle of internal friction and $c$ the cohesion. In this case the tensile strength, $s_{t}$, will be given by the following equation:

$$
S_{t}=-\frac{2 c \cos (f)}{(1+\sin (f))}
$$

Equation (10) is given by the intersection with the $\sigma$-axis of the Mohr circle representative of the stress state in the yielding powder subject to pure uniaxial tensile stress, which is the circle tangential to the yield locus on the tensile side and passing through the origin. Both cohesion $c$ and the angle of internal friction $f$ are a function of the powder consolidation and, assuming that this is very low inside an aerated powder, in equation (10) we used the extrapolation to zero consolidation of the parameter values given in Figure 4. Values of tensile strength of 45 and of $35 \mathrm{~Pa}$ were evaluated for the 14 - and $3-\mu \mathrm{m}$ powders, respectively. 
To realfore the aggregate diameter and its internal voofdage, it is possible to use the pressure drop evaluations found with the fluidization experiments. In this case the distribution of the solids mass, $m_{s}$, in the aggregates is:

$$
m_{s}=\rho_{p}\left(1-\varepsilon_{i}\right)\left(1-\varepsilon_{e}\right) \Sigma H
$$

where $\varepsilon_{i}$ is the voidage within the aggregates and $\varepsilon_{e}$ the voidage between the aggregates, $\Sigma$ and $H$ the bed cross-section and height. The mass balance of the gas is:

$$
u=u_{e} \varepsilon_{e}+u_{i} \varepsilon_{i}\left(1-\varepsilon_{e}\right)
$$

where $u$ is the gas superficial velocity, $u_{e}$ is the gas velocity in the voidage external to the aggregates and $u_{i}$ the gas velocity within the aggregates. The pressure drops through the aggregates and around them should be equal to the measured value of $\Delta P$. Therefore, within the aggregates and according to the Ergun equation for viscous regimes, we have:

$$
\frac{\Delta P}{H}=150 \frac{\mu_{f} u_{i}}{d_{p}^{2}} \frac{\left(1-\varepsilon_{i}\right)^{2}}{\varepsilon_{i}{ }^{3}}
$$

while outside the aggregates, according to the Ergun equation for intermediate regimes, it is:

$$
\frac{\Delta P}{H}=150 \frac{\mu_{f} u_{e}}{d_{a}^{2}} \frac{\left(1-\varepsilon_{e}\right)^{2}}{\varepsilon_{e}^{3}}+1.75 \frac{\rho_{f} u_{e}^{2}}{d_{a}} \frac{1-\varepsilon_{e}}{\varepsilon_{e}^{3}}
$$

In principle, the set of 5 equations (8) and (11) to (14) can be solved for each fluidization condition independently to evaluate the five unknown variables $d_{a}, \varepsilon_{i}$, $\varepsilon_{e}, u_{i}$ and $u_{e}$. However, recognizing that the internal voidage of aggregate and the aggregate diameter are powder properties that should not depend on aeration, a different procedure was used. According to this procedure, the unique value of $\varepsilon_{i}$ was found with a regression procedure on all fluidization/expansion data in which the bed appears completely fluidized. The regression objective in finding the best choice for $\varepsilon_{i}$ was to minimize the sum of relative square deviations between diameters evaluated for each powder according to (8) and those evaluated for the same powder with equations (11) to (14) at each aeration condition in the fluidization range. Aggregate diameters of 2.9 and $3.1 \mathrm{~mm}$ and aggregate voidage values of 0.547 and 0.642 were obtained for the $14-\mu \mathrm{m}$ and $3-\mu \mathrm{m}$ powders, respectively. The standard deviation between the diameters calculated according to equation (8) and according to equation (11) to (14) is about $54 \%$ and $35 \%$, which in absolute terms is very large, but not much in the order of magnitude evaluation pursued by our approach. In any case, the diame- ter values appear satisfactorily close to the observed size of aggregates to sustain the proposed procedure. Internal voidage values of aggregates are in line with the different bulk densities of the two powders. External voidage values are given in Figure 10a as a function of the aeration rate. As it appears from the figure, most of these data are in the range between 0.2 and 0.3 , and can be as low as 0.1 at low aeration rates. These voidage values represent the bed volume fraction occupied by voids between the aggregates and, therefore, they are not comparable with usual voidage values in beds of predominantly spherical particles. In the present case, these voids actually result from the gradual separation of aggregates and assume reticular low-voidage configurations such as those shown in the pictures of Figure 6 and, in principle, it can be as low as 0 when the aggregates are compacted from an external load. Total bed voidage $\varepsilon_{b}$ can be evaluated from internal and external voidages from equation (11) rewritten in the following way:

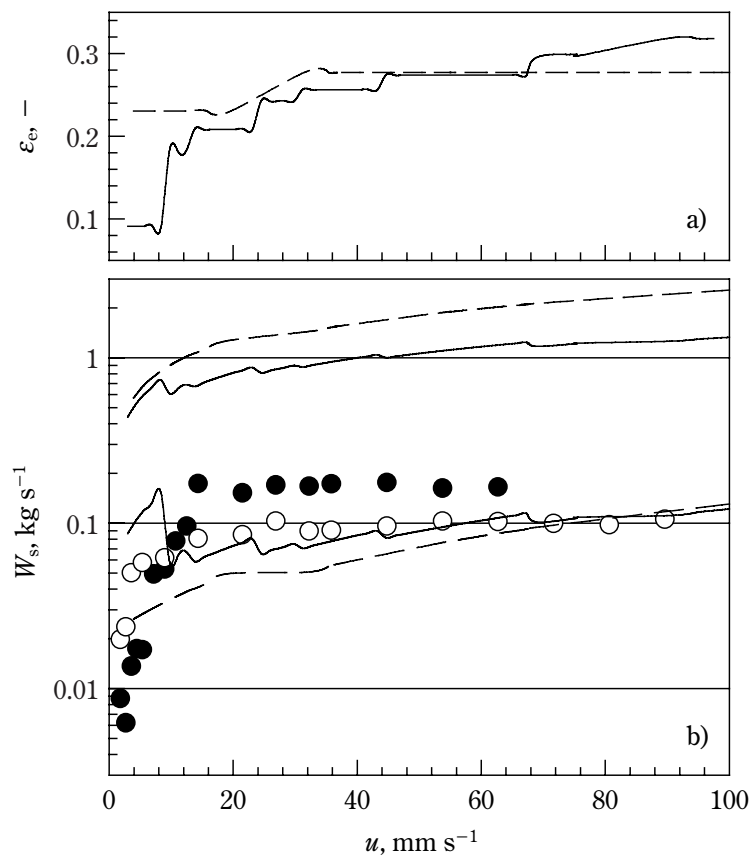

Fig. 10 Voidage values, a), and solids discharge rates, b), as a function of the aeration rate. Voidage values in a) were evaluated according to equations (8) and (11) to (14) following the procedure given in the text:,$- 14-\mu \mathrm{m}$ powder; - - -, 3- $\mu \mathrm{m}$ powder. Solids discharge rates in $b)$ refer to the following: $-14-\mu \mathrm{m}$ powder experimental data; $\bigcirc$, $3-\mu \mathrm{m}$ powder experimental data;,$- 14-\mu \mathrm{m}$ powder equation (4); - - -, 3- $\mu$ m powder equation (4); - , 14

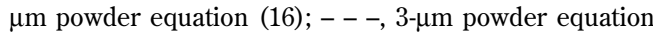
(16). 
To verify whether the aggregates play a significant role in the solids discharge, the solids discharge rate was compared with equation (4) and with the same equation in which the particle density and diameter and the average voidage are substituted with the aggregate density and diameter and the external voidage:

$$
\begin{aligned}
& W_{s}=0.55 \rho_{p}\left(1-\varepsilon_{i}\right)\left(1-\varepsilon_{e}\right)\left[a\left(Q_{f} / \varepsilon_{e}\right)^{2}+b Q_{f} / \varepsilon_{e}+g d_{o}^{5}\right]^{0.5} \\
& a=\frac{1.75}{12} \frac{\rho_{f} d_{o}}{\rho_{p}\left(1-\varepsilon_{i}\right) d_{a} \varepsilon_{e}}, \quad b=\frac{150}{8} \frac{\pi \mu_{f} d_{o}^{3}\left(1-\varepsilon_{e}\right)}{\rho_{p}\left(1-\varepsilon_{i}\right)\left(d_{a} \varepsilon_{e}\right)^{2}}
\end{aligned}
$$

Should equation (16) describe the solids discharge data better than equation (4), this would imply that aggregates keep their own individuality in the phases of solids discharge significant for the rate determination. In equation (16), the interference between the aggregate diameter and the bin outlet as the base of the correction terms of the outlet diameter in equation (4) was neglected due to the relative fragility of aggregates that would break on the orifice edge rather than interfere with the solids flow. Both equations (16) and (4) are independent of the bed height. Therefore, the application of these equations finds a partial justification in the availability of solids discharge rate data that do not depend on the bin loading conditions. The comparison between the experimental results and those predicted by using equations (4) and (16) evaluated with the voidage values resulting from equation (11) is given in Figure 10b. Inspection of this figure reveals that equation (4) largely overpredicts the experimental results. Equation (16), on the other hand, somewhat underpredicts the experimental results, but the relative deviation between experimental results and equation (16) appears smaller than between the experimental results and equation (4). Furthermore, the relative variation of the solids discharge rates between the two powders is correctly accounted for in the aggregate discharge provided by equation (16), but not by the single particle discharge described by equation (4). It appears therefore that aggregation plays an important role in the determination of the solids discharge rate. The discrepancies between equation (16) and experimental results might possibly be attributed to the tendency of the discharging bed to internal movements, which might increase the bed homogeneity and produce somewhat larger flow rates.

\section{CONCLUSIONS}

The following points summarize the main conclusions found in this work.

- Aeration was successfully used to improve the discharge of two cohesive magnesium carbonate powders differing in their particle size distribution. It appears that aeration is really effective in the promotion of solids discharge at aeration rates that can produce pressure drops through the bed comparable with the bed weight.

- The powders tested were characterized by means of fluidization experiments and by shear test experiments. The fluidization curves obtained are similar to those found by Wang et al. [15] for limestone. Similar to what was found by those authors, our direct observation of the fluidized solids evidenced the presence of clearly formed aggregates of a few millimeters in size. The presence of these aggregates was also detected in the discharging stream.

- By coupling data relative to the powder tensile strength and the pressure drops and mass balances through the fluidized bed, it was possible to correctly estimate the aggregate size by making simple hypotheses regarding the aggregate formation and their effects on aeration.

- The de Jong and Hoelen [9] equation was modified in order to evaluate the solids discharge rates as a function of the aeration rate. Also in this process aggregates seem to play an important role and, by accounting for their presence, corrections are obtained which tend towards a more accurate prediction of the solids discharge rates than what was obtained on the basis of a single particle discharge mechanism.

\section{ACKNOWLEDGEMENTS}

The authors wish to thank Ms Sara Cardaropoli for her help with the discharge and shear test experiments, Dr Diego Barletta for his help with the shear test experiments, and Mr Gianluca Bovenzi of MiMac (Italy) for providing the magnesium carbonate powders.

\section{LIST OF SYMBOLS}

$c$ cohesion $\mathrm{Pa}$

$F_{c}$ contact force N

$d_{a}$ aggregate mean diameter $\mathrm{m}$

$d_{p}$ particle mean diameter $\mathrm{m}$

$d_{o}$ bin outlet diameter $\mathrm{m}$ 
$g$ acceloration due to gravity bed height

$k$ number of the effective contacts between an aggregate and its neighbors on another layer

$m_{s}$ loaded mass of solids

$n_{c} \quad$ contact density

$Q_{f}$ aeration rate

$Q_{f_{o}}$ gas volumetric flow rate through the orifice

$Q_{s o}$ solid volumetric flow rate

$u \quad$ gas superficial velocity

$u_{e}$ gas velocity in the voidage external to the aggregates

$u_{i} \quad$ gas velocity within the aggregates

$W_{s}$ solids discharge rate

\section{Greek symbols}

$\Delta P$ pressure drops through the bed

$\varepsilon_{b} \quad$ voidage of the bulk solids

$\varepsilon_{i} \quad$ voidage within the aggregates

$\varepsilon_{e} \quad$ voidage between aggregates

$\mu_{f} \quad$ gas viscosity

$\rho_{p} \quad$ particle density

$\rho_{f} \quad$ gas density

$\Sigma$ bed cross-section

$\sigma_{t} \quad$ tensile strength

$\phi$ angle of internal friction $\mathrm{m} \mathrm{s}^{-2}$

$\mathrm{m}$

$\mathrm{m}^{3} \mathrm{~s}^{-1}$

$\mathrm{m}^{3} \mathrm{~s}^{-1}$

$\mathrm{m} \mathrm{s}^{-1}$

$\mathrm{m} \mathrm{s}^{-1}$

$\mathrm{m} \mathrm{s}^{-1}$

$\mathrm{kg} \mathrm{s}^{-1}$

$\mathrm{Pa}$

$-$

$-$

$-$

Pa s $\mathrm{kg} \mathrm{m} \mathrm{m}^{-3}$ $\mathrm{kg} \mathrm{m}^{-3}$

$\mathrm{m}^{2}$

$\mathrm{Pa}$

deg

\section{REFERENCES}

[1] Crewdson, B.J., Ormond, A.L. and Nedderman R.M.: Air-impeded discharge of fine particles from a hopper. Powder Technol., 16, pp.197-207 (1977).

[2] Beverloo, W.A., Leniger, H.A. and van de Velde, J.: The flow of granular material through orifices. Chem. Eng. Sci., 15, pp.260-269 (1961).

[3] Geldart, D. and Williams, J.C.: Flooding from hoppers: Identifying powders likely to give problems. Powder Technol., 43, pp.181-183 (1985).

[4] Geldart, D.: Types of gas fluidization. Powder Technol., 7, pp.285-292 (1973).

[5] Jenike, A.W.: Gravity flow of bulk solids. Bulletin n.108 of the Utah Engineering Experimental Station, Univer-

sity of Utah, Salt Lake City (UT), vol. 52(29) (1961).

[6] Ouwerkerk, C.E.D., Molenaar, H.J. and Frank, M.J.W.: Aerated bunker discharge of fine dilating powders. Powder Technol., 72, pp.241-253 (1992).

[7] Ferrari, G., and Bell, T.A.: Effect of aeration on the discharge behavior of powders. Powder Handling and Processing, 10, pp.269-274 (1998).

[8] Altiner, H.K.: Flow of solids from aerated hoppers: effect of aeration methods. AIChE Symp. Ser. 222, pp.55-59 (1983).

[9] De Jong, J.A.H. and Hoelen, Q.E.J.J.M.: Cocurrent gas and particle flow during pneumatic discharge from a bunker through an orifice. Powder Technol., 12, pp.201208 (1975).

[10] Massimilla, L., Betta, V. and Della Rocca, C.: A study of streams of solids flowing from solid-gas fluidized beds. AIChE J., 7, pp.502-508 (1961).

[11] Kurtz, H.P. and Rumpf, H.: Flow processes in aerated silos. Powder Technol., 11, pp.147-156 (1975).

[12] Jochem, K. and Schwedes, J.: Aeration discharge aid for silos. Proceed. of $3^{\text {rd }}$ World Congress on Particle Technology, Brighton, UK, July 6-9, paper 322 (1998).

[13] Donsì, G., Ferrari, G., Poletto, M. and Russo, P.: Gas pressure measurements inside an aerated hopper. In press on IchemE Transactions (2003).

[14] Shulze, D.: Measurement of the flowability of bulk solids. In Silos, C.J. Brown and J. Nielsen Eds, pp.18-52 (1998).

[15] Wang, Z., Kwauk, M. and Li., H.: Fluidization of fine particles. Chem. Eng. Sci., 53, pp.377-395 (1998).

[16] Pacek, A.W. and Nienow, A.W.: Fluidisation of very dense hard metal powders. Powder Technol., 60, pp.145-158 (1990).

[17] Mikami, T., Kamiya, H., Horio, M.: Numerical simulation of cohesive powder behavior in a fluidized bed. Chem. Eng. Sci., 53, pp.1927-1940 (1998).

[18] Russo, P., Chirone, R., Massimilla, L. and Russo, S.: The influence of the frequency of acoustic waves on sound-assisted fluidization of beds of fine particles. Powder Technol., 82, pp.219-30 (1995).

[19] Krupp, H.: Particle adhesion theory and experiment. Advan. Colloid Interface Sci., 1, pp.111-239 (1967).

[20] Rumpf, H.: Agglomeration. in W.A Knepper (ed.), Wiley, New York, pp.379-418 (1962).

[21] Kendall, K., Alford, N. McN. and Birchall, J.D.: Elasticity of particle assemblies as a measure of the surface energy of solids. Proc. R. Soc. Lond., A412, pp.269-283 (1987). 

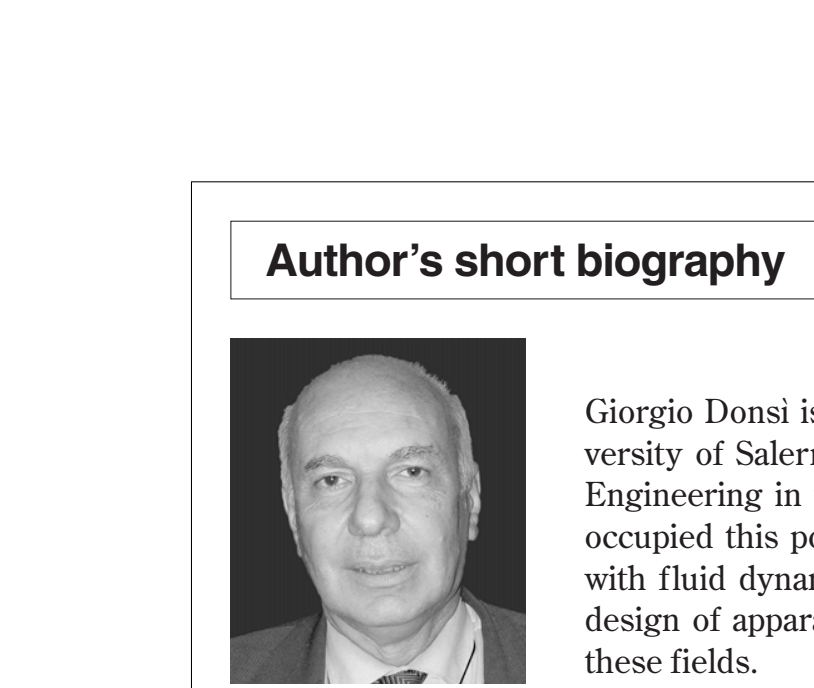

\section{Giorgio Donsì}

Giorgio Donsì is professor of Chemical Engineering since 1980. He is at the University of Salerno since 1984 where he has acted as the Dean of the Faculty of Engineering in the period from 1986 to 1995 . He was elected rector in 1995 and occupied this position until year 2001. His scientific activity is mainly concerned with fluid dynamics of heterogeneous systems, fluidisation, fundamentals of the design of apparatuses for the food industry. He is author of about 150 papers in these fields.

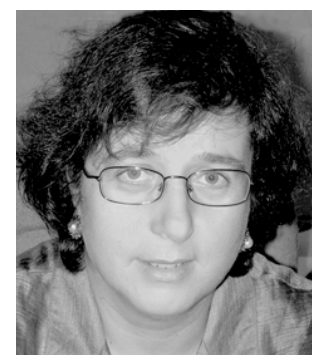

\section{Giovanna Ferrari}

Giovanna Ferrari is professor of Chemical Engineering since 2000. She is at the University of Salerno since 1986. In the same University, she is responsible of the education programme in Chemical Engineering since 1998. Author of more than 100 papers in the field of powder technology and food process engineering, her research interests are focused on the following subjects: heat and mass transfer in particulate systems, characterisation of flow properties of powders, measurement and modelling of physical and transport properties of foods, design and characterisation novel technologies for food preservation.

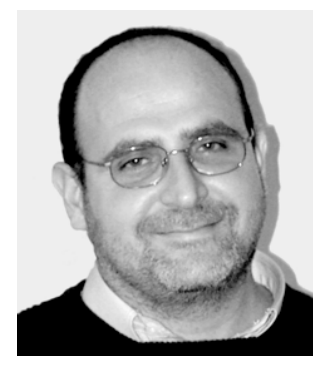

\section{Massimo Poletto}

Massimo Poletto is Associate Professor of Chemical Engineering at the Faculty of Engineering of the University of Salerno since 2001. He graduated in Chemical Engineering in 1989. In 1993 he obtained a Doctoral Degree in Chemical Engineering at the University of Naples "Federico II". From 1994 to 2001 he was Assistant Professor in the present Faculty. His scientific interests regard the fluid dynamics and mechanics of dense granular systems, in particular fluidisation and the gravity flow of powders with and without the use of aeration. In the past he also was involved in research projects on the extraction with supercritical fluids. His work appears in more than 60 papers and conference presentations.

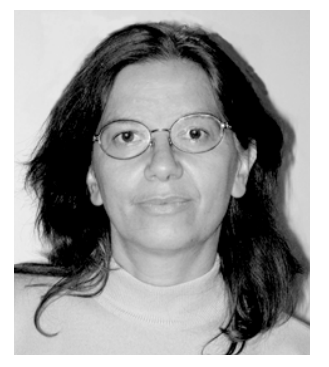

\section{Paola Russo}

Paola Russo works as research fellow at the Department of Chemical and Food Engineering of the University of Salerno. She graduated in Physics at the University of Naples and received a Doctorate Degree in Chemical Engineering at the same University with a thesis on the application of acoustic waves to fluidisation of cohesive powders. Her scientific interests mainly concern the gravity flow of cohesive powders from hoppers with and without the aid of aeration. 